\title{
Review Articles
}

\section{Insulin Treatment: A Non-Stop Revolution*}

\author{
J. Mirouze \\ Clinic of Metabolic and Endocrine Disease, University Montpellier I and Saint-Eloi Hospital, Montpellier, France
}

Ever since its introduction [1-3], insulin has provided a major stimulus for scientific research in numerous fields, including intermediary metabolism, protein chemistry, polymer biochemistry, crystallography, molecular genetics, cellular biology and endocrinology. Insulin has also been a reference model in numerous studies concerning such diverse topics as peptide hormones, viral capsid proteins, serum albumin complexes, connective tissue collagen, and toxic peptides of bee and viper venoms. Research into insulin has also made major contributions to current concepts on protein structure and biosynthesis, radioimmunoassay and sequestration of presecretory protein precursors. The target cells for insulin have provided an excellent model for the study of receptor-ligand interactions, and thus of transmitters and transmitter uptake and internalization. Insulin is also the first therapeutic agent prepared by genetic engineering. Of course its great value, and the only one to be considered here, is its spectacular therapeutic efficacy. Indeed, insulin constitutes a unique therapeutic agent which, over the past 60 years, has provided a major improvement in the prognosis of a serious disease, diabetes mellitus. It has led to the opening up of hitherto unsuspected approaches to numerous branches of medicine.

Availability of insulin has altered the natural history of diabetes mellitus with progressive malnutrition, substituting a new disease entity: insulin-dependent diabetes. A clearer view of the general consequences of diabetes has become possible, in particular the humoral and vascular repercussions. Work is currently under way concerning the degenerative complications, in particular to determine the specific roles of abnormal blood glucose levels, hormonal disturbances independent of insulin secretion and those associated with therapeutic insulin administration, direct effects upon the vascular endothelium and platelets (including their

* 14th Claude Bernard Lecture delivered to the European Association for the Study of Diabetes, Budapest, September 1982 secretions), and numerous other factors affecting coagulation and blood viscosity.

Results of work with insulin have been transposed to other forms of hormonal chemotherapy; insulin therapy can be considered as truly revolutionary, and has led to a continual advance in our understanding of physiology, pathology and therapeutics. Current studies are directed towards determination of optimal means of administration, not only to improve stabilization of blood glucose levels, but especially to control vascular degenerative disease. How and why insulin therapy has remained at the forefront of research will be discussed in turn, followed by an assessment of the current status of insulin in diabetology and general medicine as well as the various means of insulin delivery available at present and in the future.

\section{Evolution and Revolutions from Inception to the Present Day: The Insulins}

The discovery of insulin in 1921 by the Canadians, McLeod, Banting and Best, and the great success obtained with the first patient treated, Leonard Thompson, led to the very rapid introduction of insulin therapy at the Toronto General Hospital (January 1922) and quickly throughout the world. Results were spectacular, and led to the rapid and widespread acceptance of this revolutionary treatment. Usage was restricted only by limitations on production, and the years 1922-1923 thus saw the beginning of the systematic study of the pharmacology of hormones, a field which is still undergoing rapid change.

The production of insulin poses numerous logistical problems; extraction from bovine or porcine pancreas requires careful coordination with municipal or private slaughterhouses, and immediate extraction under perfectly controlled conditions. It could not be left to the initiative of isolated medical or pharmaceutical groups. The discovery of insulin thus marks one of the starting points in the prodigious development of the pharma- 
Table 1. Insulin manufacturers

\begin{tabular}{ll}
\hline $\begin{array}{l}\text { Started } \\
\text { production }\end{array}$ & Name \\
\hline 1922 & Connaught Laboratories, Canada \\
1922 & Eli Lilly, USA \\
1923 & Allen \& Hanburys, UK \\
1923 & Boots Pure Drug Company, UK \\
1923 & British Drug Houses, UK \\
1923 & Burroughs Wellcome, UK \\
1923 & Commonwealth Serum Laboratories, Australia \\
1923 & Farbwerke Hoechst, FRG \\
1923 & Nordisk Insulinlaboratorium, Denmark \\
1923 & NV Organon, The Netherlands \\
1924 & ER Squibb\& Sons, USA \\
1925 & Novo Industri A/S, Denmark \\
1938 & Swiss Serum and Vaccine Institute, Switzerland \\
1945 & Hormon-Chemie, Muenchen, FRG \\
1950 & Weddel Pharmaceuticals, UK \\
\hline
\end{tabular}

Table 2. Insulin units

\begin{tabular}{|c|c|}
\hline \multicolumn{2}{|c|}{ In the beginning $(1922-1923)$} \\
\hline & Rabbit unit \\
\hline & Mouse unit \\
\hline & Toronto unit \\
\hline & Physiological unit \\
\hline & Clinical unit \\
\hline & H unit \\
\hline & U unit \\
\hline \multicolumn{2}{|c|}{ International standards (IS) } \\
\hline 1925: First IS: & $8 \mathrm{U} / \mathrm{mg}$ amorphous insulin (Public \\
\hline & $\begin{array}{l}\text { Health Committee of the League of } \\
\text { Nations) }\end{array}$ \\
\hline 1935: Second IS: & $22 \mathrm{U} / \mathrm{mg}$ crystalline insulin (Scott) \\
\hline 1950: Third IS: & $23.9 \mathrm{U} / \mathrm{mg}$ crystalline insulin (WHO) \\
\hline 1952: Clinical unit: & $23.95 \mathrm{U} / \mathrm{mg}$ crystalline insulin (WHO) \\
\hline 1958: Fourth IS: & $24 \mathrm{U} / \mathrm{ml}$ crystalline insulin (WHO) \\
\hline
\end{tabular}

ceutical industry and particularly of insulin manufacturers; in 2 or 3 years (from 1922 to 1926) 12 laboratories from six or seven countries had started to manufacture insulin [4] (Table 1).

Development of a standardized insulin from pancreatic extracts posed several difficulties; attempts to develop a stable and reliable insulin unit took almost 40 years (Table 2 ).

Simplification of dosage with the development of insulins acting for more than $8 \mathrm{~h}$ was of historic importance for insulin therapy. The major inconvenience to the patient of two, three or even four daily injections of insulin led to the development of formulations capable of prolonging the effects of insulin for periods of at least $24 \mathrm{~h}$; thus protamine-zinc insulin was introduced in 1936. These first efforts were based upon formation of non-covalent complexes of insulin with other proteins, or preparation of insulin crystals in a slow-release form. Zinc facilitates the polymerization of insulin in both procedures; other substances including polyvinylpyrrolidone and carboxymethylcellulose were tried, but none reached the market. Protamine and zinc were thus the first agents to prolong the action of insulin successfully, and this development was followed by attempts to prolong the effects of numerous other drugs [5]. However, such studies have long since been abandoned in diabetology, since it is now apparent that delayed-action preparations do not fit therapeutic requirements. Current work is aimed at simulation of the natural pattern of insulin secretion, a constant baseline activity with a major increase following meals.

One current line of work involves insulin release controlled by blood glucose levels [6,7]; a soluble complex of sugar, insulin and lectin, stable and biologically active, has been synthetized by using modifications of methods for coupling aldehydes to primary amines. Oligosaccharides were selected according to their differential affinities for binding to concanavalin $A$ and were incubated with porcine insulin. Insulin is liberated from this complex as a function of glucose levels in the medium. Concanavalin A proved the most appropriate lectin, and after experimentation with maltose, various oligosaccharides have been studied including maltotriose, mannotriose and mannotetraose. The rate of mannotetraose-insulin release in vitro appears compatible with requirements of the diabetic. The development of such a slow release form would remove the need for other and more complex forms of administration, e.g. insulin pumps and the miniaturized artificial pancreas.

The purification of insulin is undergoing continual improvement. First, it was necessary to prepare a rigorously sterile insulin so as to avoid the insulin abscesses so frequently seen in the time of Leonard Thompson. Subsequently, insulin was subjected to further chemical purification in order to remove non-specific foreign proteins [8]. After only one crystallization of bovine or porcine insulin, the proteins present in amounts of less than $0.2 \%$ were not detectable. They consisted of pancreatic proteins or a-component, proinsulin, intermediates and insulin-dimers or b-component insulin derivates and also other hormones: glucagon, pancreatic polypeptide, vasoactive intestinal peptide, somatostatin or c-component. After a series of recrystallizations, with molecular sieve and ion exchange chromatography, the preparation contains 99\% insulin. This is mono- or single component insulin. Recently the manufacture of human insulin has opened up further prospects. At the same time, attempts to develop a rigorously sterile and chemically pure insulin have been followed by efforts to produce an immunologically inert preparation, i.e. one incapable of stimulating the formation of anti-insulin antibodies.

The recent preparation of human insulin by various advanced techniques provides the only hope for a truly non-immunogenic insulin [9]. Human insulin can be prepared using chemical procedures: extraction from human pancreas, full chemical synthesis from aminoacids, semi-synthesis from porcine insulin and finally biosynthesis (recombinant DNA technique). Novo Industri has developed an enzymatically-mediated reac- 


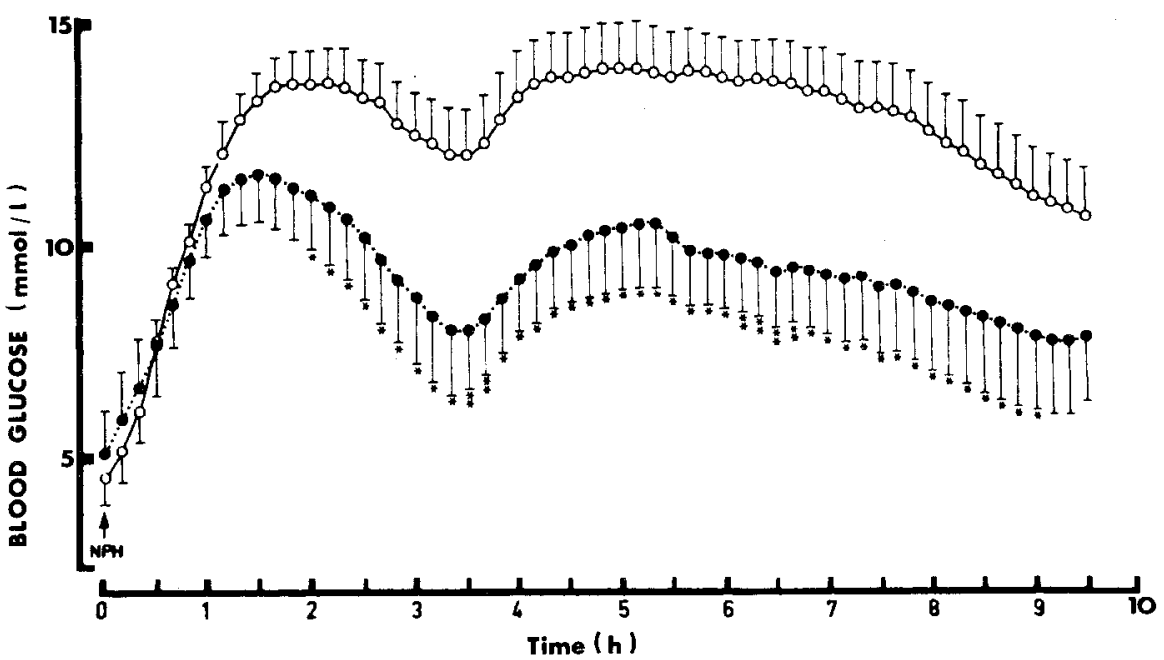

Fig. 1. Comparison between curves of continuous blood glucose monitoring after subcutaneous injection of NPH biosynthetic human insulin ( $\mathrm{O}_{-} \mathrm{O}$ ) and $\mathrm{NPH}$ purified pork insulin ( - ) in eight insulin-dependent diabetic patients (mean $\pm S E M$ ). Breakfast was taken at time $0 ;{ }^{*} \mathrm{p}<0.05$; $* * \mathrm{p}<0.01$ tion by which the terminal alanine of the B chain is selectively substituted with threonine; this semi-synthetic human insulin is obtained by conversion of porcine insulin. The Gentech company and the laboratory of Eli Lilly used genetic engineering with bacteria. Profiles for bacterial, semi-synthetic and pancreatic human insulin were identical and each gave a single symmetrical peak. These results suggest structural equivalence with human insulin, though they are not conclusive evidence that the preparation is free of isomers. The question still arises as to whether human insulin represents a true therapeutic advance for the diabetic. The first results with various human insulins have demonstrated some notable differences. However, in our experience, we have found no difference between regular porcine and human insulin, but some differences between NPH insulins (Fig.1): human NPH insulin is more efficient than porcine insulin. The differences are significant from 9 to $16 \mathrm{~h}$ [10]. The characteristics of human insulin include more rapid uptake from subcutaneous sites, decreased hepatic glucose production and increased metabolic clearance, and the virtual absence of antigenicity. It is still, however, too early to say whether these changes will present real clinical advantages. On the other hand, for prevention of the rare case of cutaneous sensitivity resulting from sensitivity to non-human insulin, these new preparations are useful [11].

Studies of non-injectable forms of insulin, designed for nasal, oral or rectal administration [12] have, until now, proved unsuccessful owing to either total or partial proteolysis. They necessitate insulin doses 7 to 10 times higher than those given by subcutaneous administration using pellets or by multiple jet injections which seem more promising, but studies of these routes are only beginning. Here the insulin is given not by subcutaneous injection but by pulsed diffusion. The efficacy of this technique is the same as that of insulin injection [13].

Modern pharmacodynamics were born with the study of insulin in diabetes mellitus: diabetes is one of the first diseases to be monitored on the basis of biochemical factors such as blood glucose and the levels of replacement hormone. To optimise therapy, rapid and reliable assay techniques for blood glucose measurement have been developed and adapted for use by the patients themselves. Individuals have thus been able to modify their therapeutic regimen, initially on the basis of clinical factors, subsequently by urinalysis and finally by self-monitoring of blood glucose. The successive advances discussed here have led to a continual improvement in insulin replacement for diabetic patients; despite this the results of insulin therapy are not yet entirely satisfactory, and technical advances are now underway which will bring about further major improvements in therapy.

\section{The Current Revolution: Insulin Delivery, Present and Future}

The history of insulin administration is a long one. The number of subcutaneous injections per day has varied with the type of insulin, the customs and the practice of each individual.

Continuous recording of blood glucose [14] showed that, despite the numerous improvements in forms of insulin then available, the normalization of blood glucose in brittle diabetic patients was very imperfect, with values very different from those seen in normal subjects.

The artificial pancreas, developed several years later (1974-1977) [15-19], clearly showed that when intravenous administration of insulin was controlled by circulating glucose levels, fluctuations in these levels could be greatly limited, blood glucose curves for poorly stabilized diabetic patients becoming superimposable upon those for normal individuals (Fig. 2). The need for a miniaturized artificial pancreas providing continuous control of glucose was clearly manifest. This dream has not yet been fulfilled and, while reliable microproces- 


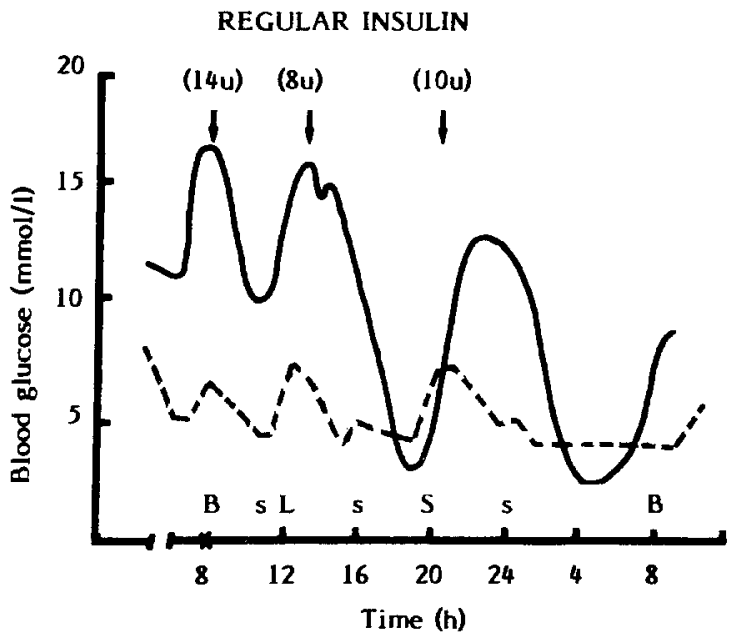

Fig. 2. Continuous monitoring of blood glucose in one diabetic patient successively treated by subcutaneous regular insulin injections $(-)$ and by artificial pancreas $(---)$. B, S, L and S respectively indicate breakfast, snack, lunch and supper.

Table 3. Continuous insulin infusion

Closed-loop system: artificial endocrine pancreas

1974: Albisser et al. [15]

1974: Pfeiffer et al. [16]

1975: Mirouze et al. [17]

Open-loop system: pumps

Short-term: venous continuous insulin delivery

1974: Slama et al. [18] Type 1 diabetes

1977: Genuth and Martin [34] Type 2 diabetes

1976: Deckert et al. [33] brittle diabetes

1976: Hepp et al. [34] Type 1 diabetes

Long-term: subcutaneous, venous or peritoneal routes of continuous insulin delivery

1978: Pickup et al. [24] Type 1 diabetes

1979: Irsigler et al. [32] Type 1 diabetes

1979: Mirouze et al. [34] brittle diabetes

sor-controlled portable insulin pumps have been developed, we do not yet have any portable and reliable system for rapid and automatic measurement of blood glucose in vivo [20].

The development of self-monitoring of blood glucose has allowed insulin doses to be adjusted by the patient himself [21]. Nevertheless, repeated subcutaneous injections of insulin, even when meticulously given, yield results far inferior to those of the artificial pancreas. In 1974, the first attempts at continuous infusion were made, initially with large and non-portable pumps providing feed-back controlled infusion rates (Table 3 ). These non-portable hospital pumps were used for periods of between several hours and several days; subsequently, portable insulin infusion pumps were employed. Diabetic ketoacidosis [22, 23], brittle diabetes [24-25] and diabetic pregnancy [26-28] were the first disorders treated. While the portable pumps do not provide automatic adaptation of insulin injection as a function of glucose levels, the delivery rate is adjustable as a function both of blood glucose levels determined by the patient himself and of foreseeable changes such as meals or physical exercise.

The intravenous continuous non-feed-back controlled insulin infusion (open loop system) was initially developed to reproduce the profile of insulin delivery given by the artificial pancreas [29-34], and soon thereafter subcutaneous continuous non feed-back controlled infusion followed. This form of treatment resembled that of the traditional subcutaneous injections [24, $25,31,35-40,46]$. The portable syringe-type infusion pumps have allowed rapid development of such techniques (Table 4). Currently, pumps for insulin delivery are being marketed by more than ten manufacturers. We have successively used several syringe-driven pumps. These pumps vary in size, weight, reservoir volume, battery life, basal rates, bolus duration and principle. Nevertheless, there remains the problem of injection route. The intravenous route presents several obstacles, not the least of which is the danger of formation of thrombo-emboli, while inflammatory reactions to subcutaneous administration necessitate changing the injection needle every 1-3 days. Furthermore, the requirement for daily handling of the syringe-system and the insulin itself led various groups to seek a more convenient route of administration and an injection system capable of longer periods of autonomy.

While non-syringe driven portable pumps are now, or will be in the near future, available on the international market, they are still few in number and very expensive (Table 4). This has greatly limited the number of patients benefiting from such devices. Although the basic technical characteristics of the systems are understood, new problems may be expected to arise, notably the stability of concentrated insulin stored at body temperature and subject to the inevitable constant agitation in ambulatory patients for periods between several days and weeks. Development of a stabilized form of insulin meeting these requirements is difficult [ $41-43$ and unpublished observations]. Ordinary forms of insulin aggregate into high molecular weight polymers, yielding a crystalline precipitate with inactivation and yellowing of the solution, as well as obstruction of the catheter. The optimal anti-precipitant has thus far proved to be a mixed polymer of polyethylene glycol and polypropylene glycol; satisfactory results have also been obtained by addition of amino acids (glutamic or aspartic), or by the formation of insulin sulphates. Stabilization of insulin has also been attempted using the surfactant Genapol. It is of course necessary that the insulin reservoir does not denature its contents; the current preference is for polyethylene or titanium. These essentially technical difficulties no longer constitute a major stumbling block and are rapidly yielding to new developments in insulin chemistry. The problems are different with portable and implanted pumps.

Three routes are possible: subcutaneous, intravenous and intraperitoneal. With continuous intraperito- 


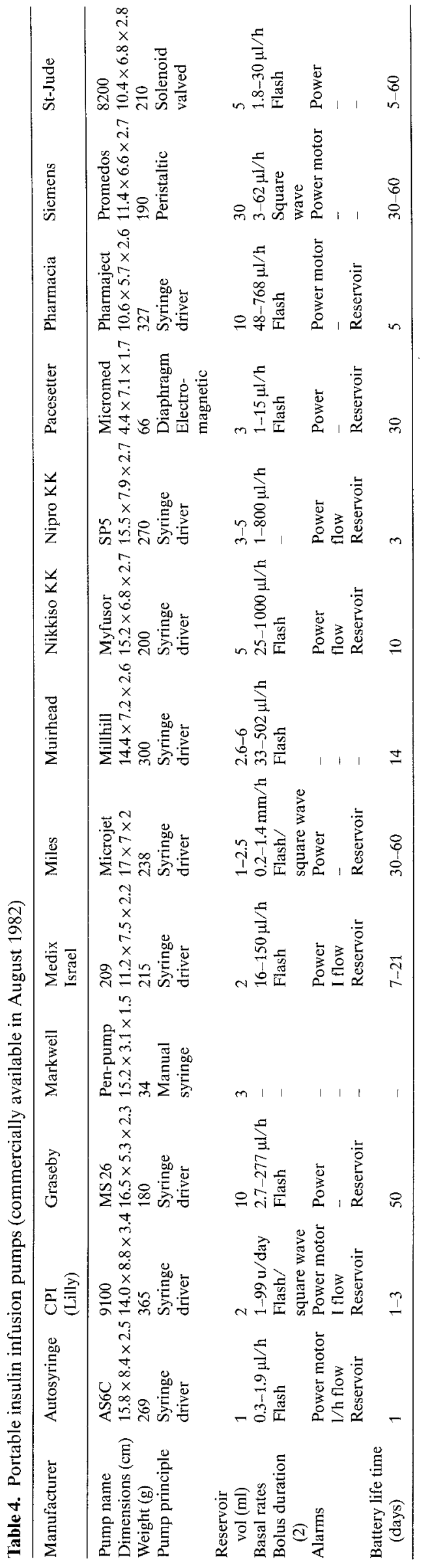

neal and subcutaneous insulin infusion, the level of free insulin obtained is lower than with the intravenous route $[44,45]$. Despite several difficulties the intraperitoneal route was considered preferable $[29,31,33,47]$.

Intraperitoneal infusion requires a considerably more elaborate technique than venous catheterization (carried out by the nursing personnel) or subcutaneous injection (carried out by the patient himself). For the comfort and safety of the patient, peritoneal catheterization requires full sterile surgical procedures similar to those used in peritoneal dialysis. Our group have used polyethylene catheters covered with a thin layer of silicon and a dacron sleeve-cover to prevent bacterial infection at the point of entry and to facilitate attachment to the skin: $10-15 \mathrm{~cm}$ of catheter was intraperitoneal, $5 \mathrm{~cm}$ in a subcutaneous tunnel, with the external $20 \mathrm{~cm}$ providing attachment to the pump. Access was paraumbilical [48]. It is obvious that the peritoneal route is useful only if the external end of the catheter is not subjected to frequent manipulation. Therefore, this procedure can be developed only if pumps with a long autonomy are used.

Development of implantable pumps [47, 49-53] constitutes a logical next step as the above-mentioned obstacles are overcome, and patients with brittle diabetes may derive substantial benefit from prolonged use of portable pumps. Relatively few patients have thus far benefitted from these devices (Table 5), and only a few groups have the necessary level of experience with even standard portable or rotary pumps. Of course, implantable pumps, apart from obviating the problems of catheter insertion, in no way resolve the major constraint of the portable systems: frequent self-monitoring of blood glucose, adjustment of basal and post-prandial insulin administration rate several times daily, and filling of the insulin reservoir every $2-3$ weeks. Our experience is currently limited to a single patient, now reaching the end of the first year of treatment. The pump was implanted in a 23-year-old subject in whom a spectacular improvement had been attained with 15 months on a portable pump. The pump was placed beneath the abdominal muscles, with the catheter emptying into the peritoneum; the reservoir being filled every 3 weeks. The patient monitored her own glucose levels seven times daily and could choose the basal rates and prandial dose with an external programmer. She has now attained a satisfactory degree of control of blood glucose levels and there has been a complete cessation of episodes of severe hypoglycaemia or ketoacidosis, along with a regression of incipient macular retinal oedema; her quality of life has been completely transformed [47].

The development of such biomedical technology, from hospital pump to implantable pump, can be justified on the basis of various scientific, medical and sociological criteria. Nevertheless, definitive evaluation of the validity of these techniques is not yet available, and it should be noted that the majority of continuous infusion treatment regimens have been discontinued after 
Table 5. Current status of implanted insulin pumps in diabetic subjects

\begin{tabular}{|c|c|c|c|c|c|}
\hline Manufacturer & Siemens & Metal Bellows & Sandia & Medtronic & Pacesetter \\
\hline Pump name & $\mathrm{PFA}_{1}$ & Infusaid & Sandia & $?$ & $?$ \\
\hline Dimensions $(\mathrm{cm})$ & $8.5 \times 6.0 \times 2.2$ & $8.6 \times 2.4$ & $?$ & $7.0 \times 2.8$ & $8.1 \times 2.0$ \\
\hline Weight filled (g) & 180 & 225 & 280 & 180 & 170 \\
\hline Pump principle & Peristaltic & Vapor-powered bellows & Peristaltic & Pulsatile solenoid & Peristaltic \\
\hline Reservoir volume (ml) & 10 & 47 & 5 & 20 & 7.2 \\
\hline Battery life-time (years) & 1 & - & $?$ & 5 & 10 \\
\hline Flow rate & Variable & Constant & Variable & Variable & Variable \\
\hline Alarms & 0 & 0 & $?$ & Flow alarm & Flow alarm \\
\hline Remote control & Yes & No & Yes & Yes & Yes \\
\hline Number in function & 3 & $>20$ & 3 & 0 & 0 \\
\hline Date of first human implantation & April 1981 & December 1980 & January 1981 & - & - \\
\hline Route of administration & IV $/$ IP & IV & IP & - & - \\
\hline
\end{tabular}

Status as at August 1982

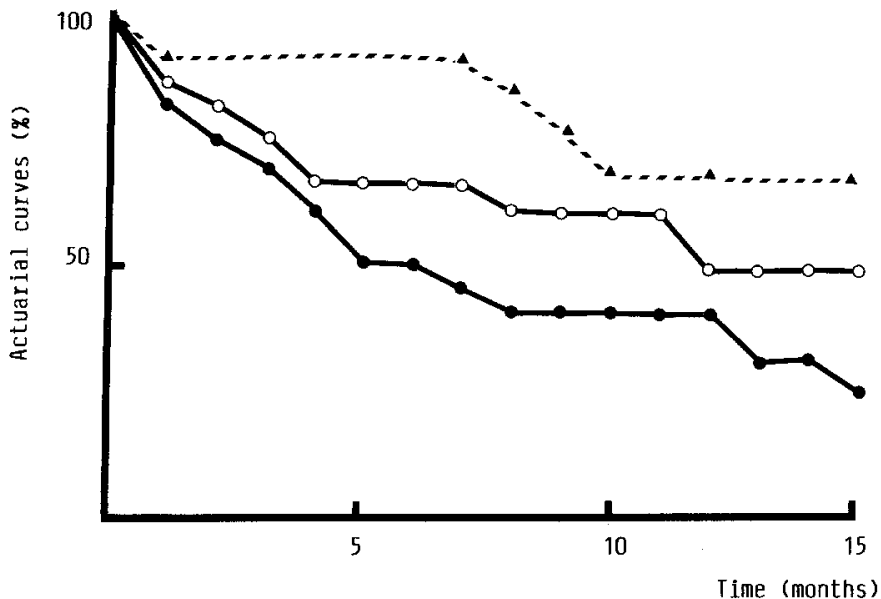

Fig.3. Actuarial curves showing pump life time $(\mathrm{O}-\mathrm{O})$, duration of the pump utilization per patient $(-)$ ) and peritoneal catheter life time $(\boldsymbol{\Delta}---\mathbf{\Delta})$.

only a few months; it is exceptional for them to last more than 1 or 2 years. Many of these studies have been limited to a few weeks or months, and while they have certainly yielded new and useful insights into the pathological process, their duration is insufficient to judge current methods of long-term insulin infusion.

\section{Clinical Evaluation of Insulin Delivery Techniques ... Tomorrow's Revolution?}

Grave complications of continuous intraperitoneal insulin infusion have been very infrequent, and we have had no deaths. The 24 deaths reported in the United States in patients receiving subcutaneous insulin infusion have not yet been fully analysed, and there is no evidence for a causal relationship between death and the infusion procedure $[54,55]$. The possibility of amyloid degeneration as reported in dogs is not necessarily linked to the method of administration [56].

Localised infections and reactions at the catheter entry site quickly yield to simple therapeutic measures $[57,58]$ and we have seen no peritonitis. The frequency of peritonitis, reported by our nephrologists in the uraemic diabetic patients treated by home intermittent or ambulatory continuous peritoneal dialysis, is only one per 17 patient-years. The volumes of fluid used for dialysis and insulin infusion are very different. The frequency of infections at the entry site, in all our experience, is only one per two patient-years.

Technical problems of many types have been quite common. We have had one pump failure and one catheter problem every two patient-years. Catheter problems consisted of partial exteriorisation by involuntary traction of the catheter (twice) and of external rupture (twice) but repairs have always been possible without needing to remove the catheter or stop the infusion. Using stabilized forms of insulin, early obstruction of the catheter has not been seen. It has never been necessary to remove the catheter before 13-15 months of usage. The actuarial curves (Fig.3) show the frequency of pump failure. The first curve indicates the pump life in 25 diabetic patients treated by intraperitoneal infusion. One year after the beginning of treatment, one of every two pumps was out of order. The second curve indicates the duration of pump utilisation per patients; one year after the start of treatment, $40 \%$ of patients were still using the same pump. It is common, in our experience, for a pump to fail to function in one patient but to work in another one. Thus three patients have had four pumps; the life of the first two pumps was $3.6 \pm 1.1$ months. Five patients have had two pumps; the life time of the first pump was $2.2 \pm 1.1$ months. The mean duration of utilisation of pumps used but not out of order was $3.9 \pm 0.9$ months. The life of pumps out of order was $5.4 \pm 1.7$ months. For 24 patients treated during 16 patient-years we have used 35 pumps. The third curve indicates the peritoneal catheter life. One year after the start of infusion, $74 \%$ of patients were still using the same catheter.

In terms of quality and regularity of insulin administration, hypoglycaemia [59-60] and ketoacidosis due respectively to excessive or inadequate insulin dosage could be attributed either to episodic failure or to patient error. Nevertheless, in our experience, these are far less frequent than with conventional therapy. Ketoacid- 


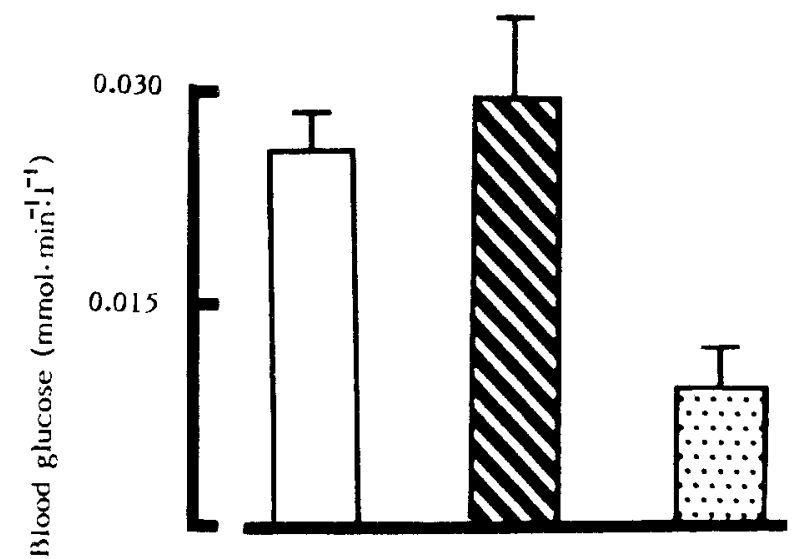

Fig.4. Rate of spontaneous blood glucose rise after interruption of insulin administration in brittle diabetic subjects treated by subcutaneous injection $(\square, n=60)$, in Type I diabetic patients treated with insulin infusion by subcutaneous $(\mathbb{N}, \mathrm{n}=8)$ and intraperitoneal ( 圆 , $\mathrm{n}=5$ ) routes. Results are mean $\pm \mathrm{SD}$.
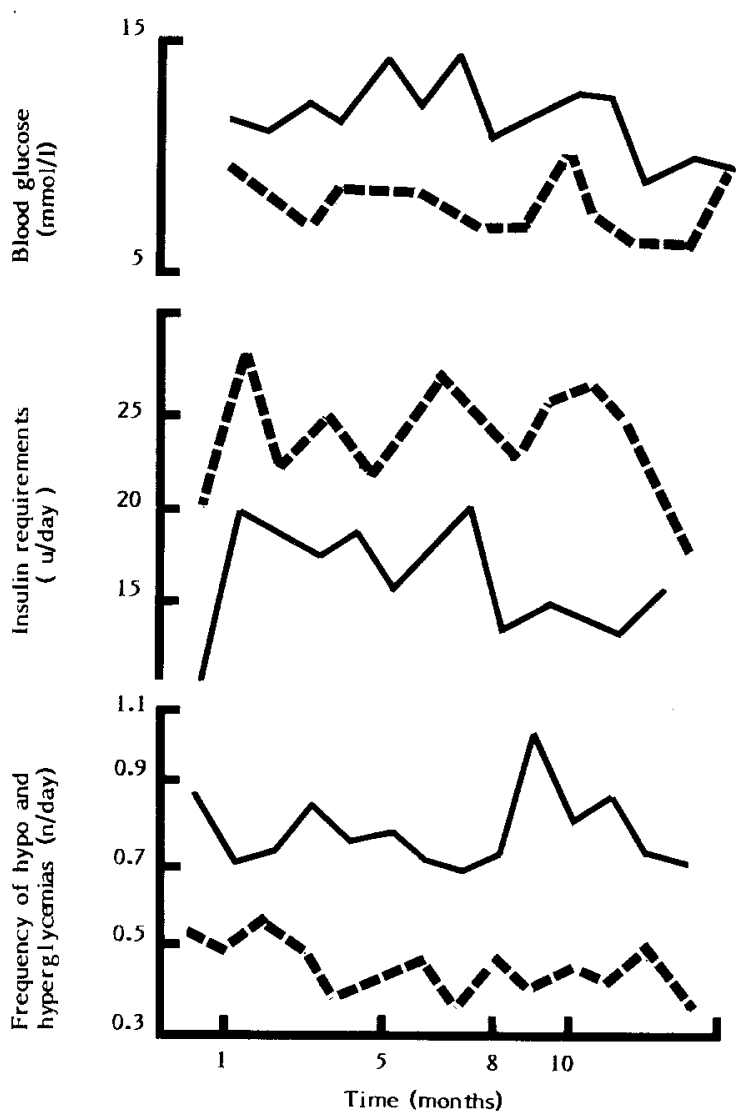

Fig.5. Blood glucose levels, insulin requirements and frequency of hypoglycaemia $(<2.8 \mathrm{mmol} / 1)$ and hyperglycaemia $(>11.1 \mathrm{mmol} / \mathrm{l})$ in 23 diabetic patients treated with intraperitoneal insulin infusion. Fasting time $=---$ and meal time $=-$.

osis is rare and, in our experience, its rate of onset in these patients did not differ from that usually seen in other circumstances. Figure 4 represents the rate of blood glucose rise $\left(\mathrm{mmol} \cdot \mathrm{min}^{-1} \cdot \mathrm{l}^{-1}\right)$ in three different circumstances; the first, in 1973, during analysis of brit- tle diabetes by continuous blood recording after withdrawal of insulin [61]; the second experiment, in 1982, $6 \mathrm{~h}$ following nocturnal voluntary interruption of a continuous subcutaneous insulin infusion [62]. The third reflects our current personal experience, $4 \mathrm{~h}$ after involuntary pump failure in diabetic patients treated by intraperitoneal infusion. Failure rates between the three groups are not significant; the rather lower rate in our group was perhaps related to the peritoneal route of insulin administration and education of patients on its use. None of the complications thus far reported should constitute a contraindication to widespread use of these techniques.

Is the control of blood glucose superior to that obtained by conventional subcutaneous injections? Various authors have reported contradictory data [63-65] and, indeed, analysis is difficult since therapeutic approaches are far from standardized. While the subcutaneous route has been used the most frequently, consistency of effect seems to be better with intravenous or intraperitoneal administration. Modification of administration rates at meal-time has varied greatly, as have both the evaluation criteria chosen and indeed the initial clinical condition of the patients themselves.

Taking only insulin-dependent diabetic patients and evaluating results not only on the basis of the usual clinical criteria, but also by precise determination of residual endogenous insulin secretion (static or dynamic assay of urinary or blood C-peptide), we have found infusion to be clearly superior to conventional techniques, especially when administration was via the peritoneal route, using peristaltic pumps, and in brittle diabetic patients. Our evaluation criteria included seven glucose values daily, four pre-prandially and three at meal times. We have calculated the mean meal-time and pre-prandial blood glucose level, as well as the frequency of 'hypoglycaemia' ( $<2.8 \mathrm{mmol} / \mathrm{l})$ and 'hyperglycaemia' ( $>11.1 \mathrm{mmol} / \mathrm{l}$ ) (Fig. 5). These long-term studies have included 23 patients for a total of 16 patient-years and 50000 blood glucose levels, analysed by computer. The range of blood glucose levels for meal times was $6.4-8.3 \mathrm{mmol} / \mathrm{l}$, and pre-prandially $5.6-7.2 \mathrm{mmol} / \mathrm{l}$. The range of insulin requirements for meal times was 15-20 units/day and decreasing progressively; for the basal state, it was 24-28 units/day and very stable. The frequency of 'hyperglycaemia' varied from 0.8 to 1.1 times/day, the frequency of 'hypoglycaemia', from 0.4 to 0.6 times/day. Similar results were obtained in the patient treated with a portable pump for 14 months, and then an implanted pump for 11 months (Fig.6). Blood glucose levels and frequencies of hyper- and hypoglycaemia were similar in the two circumstances. Insulin requirements were less with the implanted pump. The number of insulin units was almost half with the implanted compared with the portable pump in basal as well as in prandial periods, but her weight was falling with the implanted pump, and is now 'ideal' following a progressive weight loss of $10 \mathrm{~kg}$. 

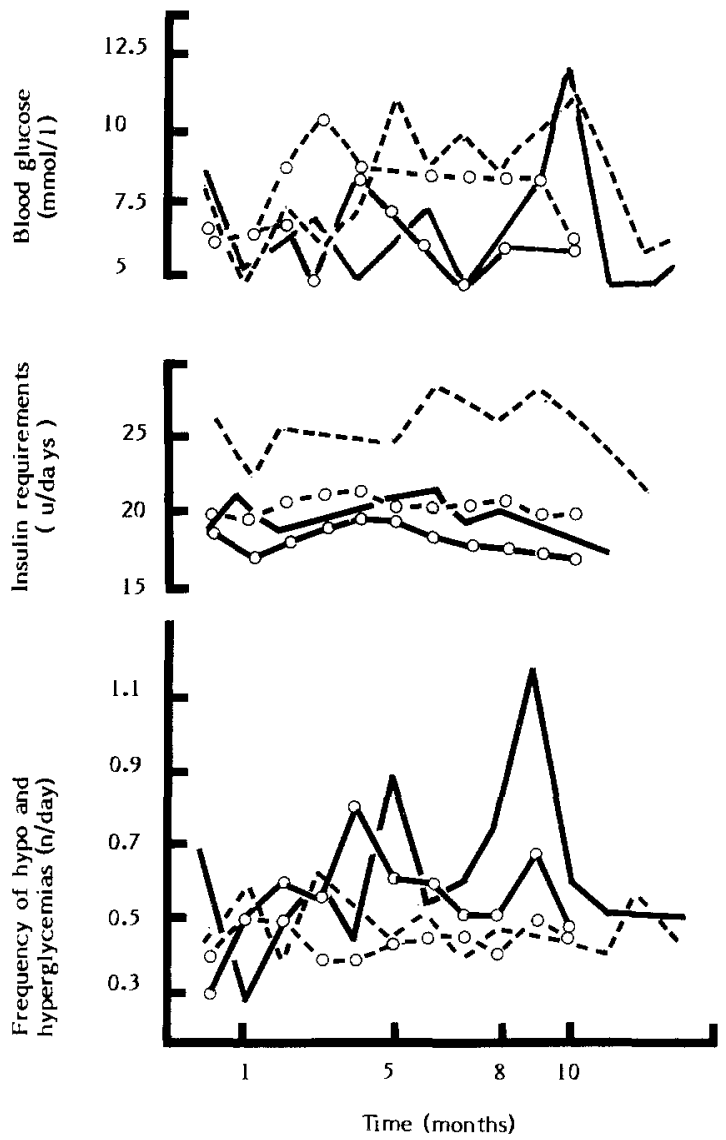

Fig. 6. Data are presented as in Figure 5 in one diabetic patient ( 23 years) during the periods of treatment with portable pump (-,- - ) and implanted pump $(\mathrm{O}-\mathrm{O}, \mathrm{O}--\mathrm{O})$.

The benefits of short-term insulin infusion, with or without feed-back control by blood glucose levels, have been confirmed by the increased frequency of complete remission during the initial stages (within 6 months of onset) of acute-onset ketoacidosis-prone diabetes [66-68]. Complete withdrawal of insulin therapy for

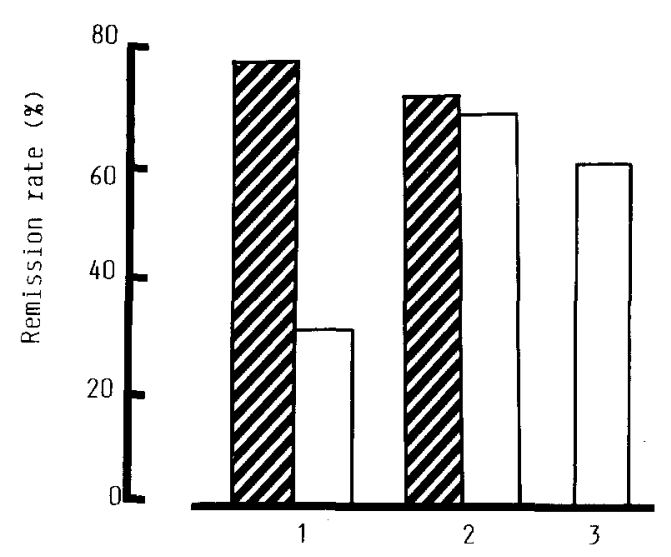

Fig. 7. Remissions in acute onset ketotic diabetes as obtained by artificial pancreas ( $\square$ ) and infusion pump ( $\square$ ) in the first (1) period (1976-1979, $\mathrm{n}=33)$, second period (2) $(1979-1980, \mathrm{n}=41)$ and third (3) period (1981-1982, $\mathrm{n}=44)$.

more than 3 months has, in our experience, been possible seven times more frequently with infusion techniques than with classical injections. Our results relate to three different periods: in the initial period (1976-1979) we were mainly using the artificial pancreas; in the second period, a closed loop system as well as open-loop system (Fig. 7); in the third period, mainly an open-loop system. The differences were not significant. Quality of early glucose control also influences the remission rate: much of the success of the artificial pancreas can be attributed to this. Our early experience, using a pre-programmed insulin pump, led to only $30 \%$ of remissions, while the use of more precise programmes over the 2 years $1979-1980$, more than doubled this rate to $71 \%$, a frequency similar to that obtained by the artificial pancreas. Current results, with the exclusive use of insulin infusion pumps are similar. These complete remissions constitute an especially positive result, and every effort must be made to prolong them beyond the

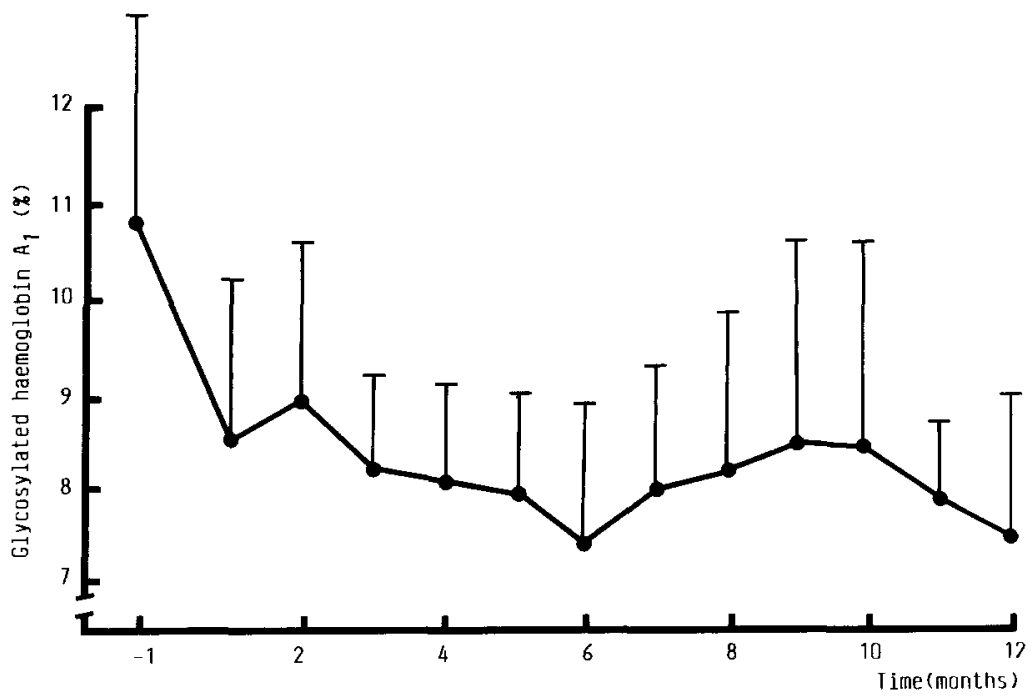

Fig. 8. Glycosylated haemoglobin $A_{1}$ in 22 patients treated with continuous insulin infusion. 
11-12 months seen in our study, in particular by the use of an immunological approach. Such attempts have, however, in our experience, been ineffective.

Glycosylated haemoglobin levels reflect overall therapeutic efficacy rather than efficacy of a particular technique. In stable diabetes, all approaches appear to yield similar results, and in particular no differences in glycosylated haemoglobin levels were noted between patients on discontinuous or continuous subcutaneous protocols. On the other hand, we have found that continuous peritoneal infusion in brittle diabetes was superior to all other approaches. In our diabetic group, the level of glycosylated haemoglobin remained normal from the beginning of the infusion (Fig. 8).

Free insulin levels do not provide an index of therapeutic efficacy; while these levels were lower in patients receiving infusion than in those undergoing the standard subcutaneous treatment, they were still three times as great as in normal healthy subjects [31].

The disturbances in lipids frequently seen in untreated or brittle diabetes mellitus are improved by any administration of insulin capable of controlling the disease. Insulin infusions not only decrease cholesterol and triglyceride levels, but especially increase high density lipoprotein cholesterol and apoprotein A (A1, A2, E) [69-70]. No difference was observed between subcutaneous and intraperitoneal infusions. In our experience of the peritoneal and subcutaneous routes lipid levels were improved after 6 weeks of insulin infusion and very near the normal range. The difference in ratios of apolipoprotein A to apolipoprotein B before and after six weeks infusion is significant [71].

Levels of the principal hormonal factors (such as adrenaline, glucagon, growth hormone, somatomedin and cortisol) involved in regulation of blood glucose and notable in the control of hypoglycaemia, were analysed using both static and dynamic models [72-78]. After 15 days of insulin infusion, patients subjected to induced hypoglycaemia presented a less sustained release of these hyperglycaemic factors, similar to that which is seen in normal subjects but also in diabetic patients conventionally treated with human insulin.

Circulatory humoral factors which may be involved in the pathogenesis of diabetic angiopathy have not yet been sufficiently studied. Among the numerous factors which should be checked periodically during chronic insulin administration, one should note endothelial factors such as Von Willebrand's factor, plasminogen, factor VIII, prostaglandin A 12 and prostacyclin: platelet factors (such as $\beta$-thromboglobulin, thromboxane A2), along with functional values for adhesiveness and aggregability, plasma factors (such as viscosity, fibrinogen, $\beta$-2-globulin) and plasma fibrinolytic activity. Finally, erythrocytes may be implicated in the pathogenesis of angiopathy, and factors such as erythrocyte deformability, 2-3-diphosphoglycerate, erythrocyte aggregation, haemolysis and haemoglobin $\mathrm{A}_{1 \mathrm{c}}$ should be considered. Our very limited experience has shown that, within 6 weeks, insulin infusion can improve serum lipid and lipoprotein values, but that this time period is insufficient for correction of disturbed platelet function and $\beta$-thromboglobulin [71].

The various biochemical factors analysed would seem to suggest the superiority of insulin infusion. Nevertheless, it is important to determine whether this is in keeping with the clinical phenomena actually observed. On the basis of published reports and considering our limited experience with portable infusion pumps, even once they are well-installed, degenerative phenomena do not appear to be much influenced [79-83 and unpublished observations].

In diabetic retinopathy, there is a notable aggravation of the initial lesions without necessarily visible vascular pathology in patients initially free of retinal degeneration. In our limited experience of five patients with proliferative diabetic retinopathy, there was a single case of rapid decompensation with haemorrhage into the lens a few weeks after the beginning of insulin infusion. Of two patients presenting with frank macular oedema without proliferation, one appeared to stabilise after 1 year of treatment, the second showing a completely normal macula after a similar period.

Advanced diabetic nephropathy is not reversed by prolonged insulin infusion, and deterioration of renal function continues until complete failure requires dialysis or transplantation [83-85]. The overall effect may be beneficial because the mortality rate is greater in the diabetic group treated with oral drugs than with insulin [86].

Peripheral and autonomic neuropathy appear to be improved by infusion of insulin with a regression of pain, paraesthesia, aesthenia and loss of gastric tone within a few months $[87,88]$; on the other hand, orthostatic hypotension, impotence, neuropathy of the bladder and diabetic diarrhoea appear to be unchanged. Thus advanced stages of degeneration are usually refractory to improved control showing a progression independent of any subsequent changes in control of blood glucose, but improvement is always possible.

However, initial results [83] suggest that functional changes in these same organs occurring early in the course of diabetes, and in the absence of any clear sign of pathological degeneration, are highly sensitive to improvement in glycaemic control; macular recovery time as measured by nyctometry, development of electroretinographic potentials, and fluorophotometry of the posterior vitreous, all show a consistent improvement during correctly managed insulin infusion. All of these parameters are unaffected by or worsen with conventional insulin therapy. Glomerular filtration as measured by direct intravenous injection of ${ }^{51} \mathrm{Cr}$-labelled EDTA, urinary albumin excretion and albumin levels measured by radioimmunoassay, all show normalization after 6 months in diabetic patients undergoing insulin infusion while, once again, all showed deterioration after the same period of conventional subcutaneous ad- 
ministration. After 1 year of study, this improvement is generally maintained when complete control of blood glucose has been possible, but aggravation becomes more marked in cases of inadequate control, and results remain unchanged at intermediate levels of control. Nerve condition velocity, systematically measured in the absence of manifest neuropathy, shows an improvement in both sensory and motor function in patients undergoing infusion; there were no such changes in the group receiving subcutaneous injection despite the comparable degree of control attained in the two groups.

In summary, the findings to date indicate that insulin pump treatment is a feasible means, not only of restoring a normal metabolic milieu, but also of improving some aspects of degenerative disorders in insulin dependent diabetics. With retinopathy, precise diabetic control obtained with the insulin pump should stop the evolution of lesions, bring about early reversal of small pre-proliferative lesions and prevent their development. In nephropathy, it will not reverse advanced lesions. In neuropathy, it will improve pain, paresthaesia, asthenia and gastroparesis but will not improve orthostatic hypotension, impotence and bladder paresis. In all cases, precise diabetic control prevents functional changes which are presumed to be early indices of microvascular disease.

The efficacy of insulin infusion thus appears to be very much a function of the stage that the diabetic pathology has reached. If confirmed, these results will pose some particularly delicate questions. Indeed, these preliminary results would seem to indicate that insulin infusion pumps are justified for a very large number of insulin-dependent diabetic patients. This is in contrast with the small and highly selected population currently benefitting from these techniques: patients for whom diabetes constitues a particularly severe handicap, those threatened with severe complications, perfectionists who seek absolute control of their pathology, and so on. The efficacy of insulin infusions must also be appreciated by the patients themselves. The patient's view may be summarised by the following advantages, in order of priority: blood glucose stabilisation, flexible meal times, absence of subcutaneous injections, more flexibility of diet; $80 \%$ feel better. Disadvantages are: difficulty in washing, obligatory skin dressings, frequent home blood testing, discomfort and medical dependency. Thus the widespread adoption of insulin infusion would require the resolution of several major problems.

Simplification of all the technical factors involved in continuous infusion is a major goal not only for the physician, but also for patients, as shown by a confidential survey. Indeed, psychological assessment of the patients treated with insulin infusion gives very clear results: they show no desire to return to conventional therapy, enthusiasm about their treatment, no embarrassment concerning advertisement of their diabetic condition, no sexual maladjustment, less severe depres- sion and anxiety, and no need for a formal support group. This last point is the most important. Such simplification will be possible only by the development of a sustained release form of insulin controlled by circulating glucose levels (lectin-sugar-insulin complex) or, should this prove impossible, by the development of a reliable glucose sensor for a miniaturized portable or implantable artificial pancreas. Unfortunately, I do not believe that either of these systems will become available in the near future.

A more egalitarian organization of health care delivery will be necessary for diabetic patients to have access to appropriate therapeutic measures. Pumps, for example, are quite expensive. The cost of hospitalisation for diabetes in Paris today is higher than for cirrhosis of the liver, delivery, stroke, chronic renal failure, hip fracture or myocardial infarction [89]. Yet insulin forms only a very minor part of hospital drug costs, its price being only one-thirty-fifth of that of the most expensive agents such as heparin and antibiotics. The cost of specific medications for diabetes are among the lowest. All this will change with development of the new delivery systems.

We have recently established an association of patients receiving continuous therapeutic infusion in the Languedoc Roussillon region (Association des Malades Traités par Infusion Médicamenteuse) in order to facilitate relations between the patient and the Social Security Administration. The financial report in 1982 showed an annual turnover of more than US \$200000 and the equipment grants in 1982 , were US $\$ 230000$. The association received a large subsidy for the purchase of our first portable pumps, and the Social Security Administration now provides a monthly sum for each patient covering purchase, maintenance and function of the pumps. The association thus frees the patient of any supplementary financial burden, and there are now 25 members undergoing chronic insulin infusion. All are treated by continuous intra-peritoneal insulin infusion.

Finally, ongoing education of patients is necessary, not so much in terms of availability of medical care (which all patients seem to be aware of, regardless of socio-economic class or degree of education), but in terms of the need for prophylaxis of possible degenerative complications.

Thus we now find ourselves approaching a crossroads, and we are more and more frequently faced with a cruel dilemma: major therapeutic means are available to optimise the treatment of diabetic patients whom we know to be prone to the development of severe pathology, but this only after variable, and sometimes very long periods of time. To what extent must the physician recommend the use of these new and very difficult therapeutic approaches, the superior efficacy of which will probably be confirmed in coming years? Is it necessary to orientate the patient towards a highly cumbersome procedure while other, far simpler, techniques are avail- 
able, despite the fact that these older procedures may be considerably less efficacious in the long run? Today's problems, of availability and particularly of ethics, confronting the diabetologist wishing to use insulin infusion technology will be tomorrow's problems for many other specialists. Insulin is in the forefront of therapeutic technology, and break-throughs for insulin mean advances in so many other areas of treatment.

We should for a moment reflect on the philosophy of Claude Bernard, whom we honour each year in our Association. Ernest Renan [90], during his maiden speech to the Academie Française on the 3 April 1879, gave the obituary of Claude Bernard, whom he had succeeded, and said of him, in alluding to his strength of personality: "It is not without good reason that it is impossible to become a great poet without idealism, a great artist without faith and love, a great writer without logic, an eloquent speaker without a passion for goodness and liberty". Do you not think that we should add, in remembrance of Claude Bernard and of the problems of treating diabetes, that it is even more difficult to be a great doctor since it requires the embodiment of logic, science, faith and love for your neighbour, a passion for what is good and the ambition to improve?

\section{References}

1. Steiner D (1977) Insulin today. Diabetes $26: 322-340$

2. Levine R (1981) Insulin action: 1948-1980. Diabetes Care 4: $38-44$

3. Marliss E (1982) Insulin: sixty years of use. New Engl J Med 306: 362-364

4. Jackson JGL (1982) Insulin: 1922-1982. IDF Bulletin 27:4 8

5. Ritschel WA (1973) Parenteral dosage forms with prolonged action. In: Ariens J (ed) Drug design. Academic Press, New York, pp $75-92$

6. Brownlee M, Cerami A (1979) A glucose-controlled insulin delivery system: semisynthetic insulin bound to lectin. Science 206: 1190-1191

7. Brownlee M, Cerami A (1982) Insulin oligosaccharide complexed to lectin. Diabetes 31 (Suppl 2): $51 \mathrm{~A}$

8. Schlichtkrull J (1977) Purity and antigenicity of insulin preparations. Acta Paediatr Scand 270: (Suppl 270) 37 (Abstract)

9. Skyler JS, Raptis S (1981) Symposium on biosynthetic human insulin. Diabetes Care 4: 139-264

10. Mirouze J, Richard JL, Rodier M, Monnier L, Cavalie G, Soria K (1982) Comparative study of NPH human and porcine insulins in diabetic patients. Diabetes Care 5: 60-62

11. Mirouze J, Monnier L, Rodier M, Balducchi JP, Orsetti A, Clot J (1982) Urticaire insulinique chronique: grande efficacité des insulines humaines. Nouv Presse Med. 11: 3327-3330

12. Baron H, Berry E, Eldor A, Kidron M, Raz I, Ziv E (1982) Enteral administration of insulin in rat and human. Diabetes 31 (Suppl 2): $52 \mathrm{~A}$

13. Champion M, Becks G, Roger NW (1982) Multiple jet injections of insulin in insulin-dependent diabetes mellitus. Diabetes 31: (Suppl 2) 52 A (Abstract)

14. Mirouze J, Jaffiol C, Sany C (1962) Enregistrement glycémique nycthéméral continu dans le diabète instable. Rev Fr Endocrinol Clin Nutr Metab 3: 337-353

15. Albisser AM, Leibel BS, Ewart BS, Davidovac Z, Botz CK, Zingg W (1974) An artificial endocrine pancreas. Diabetes 23: 389-396
16. Pfeiffer EF, Thun Ch, Clemens AH (1974) The artificial beta cell: a contribution control of blood sugar by external regulation of insulin infusion (glucose controlled insulin infusion system) Horm Metab Res 6: 339-342

17. Mirouze J, Selam JL, Pham TC, Cavadore D (1977) Evaluation of exogenous insulin homeostasis by the artificial pancreas in insulin dependent diabetes. Diabetologia 13:273-278

18. Slama G, Hautecouverture M, Assan R, Tchobroutsky G (1974) One to five days of continuous intravenous insulin infusion on seven diabetic patients. Diabetes 23: 732-738

19. Kraegen EW, Campbell LV, Chia YO, Meler H, Lazarus L (1977) Control of blood glucose in diabetics using an artificial pancreas. Aust NZ J Med 7: 280-286

20. Soeldner JS (1982) Symposium on potentially implantable glucose sensors. Diabetes Care 5: 147-284

21. Arlot S, Richard JL, Selam JL, Chaballier L, Mirouze J (1983) Autosurveillance glycémique: lecture visuelle ou automatisée. Ann Med Interne (In press)

22. Mirouze J, Mion C, Monnier L, Beraud JJ, Selam JL (1976) Traitement de la céto-acidose diabétique par infusion continue d'insuline. Nouv Presse Med 5: 2444-2446

23. Heber D, Molitch ME, Sperling MA (1977) Low dose continuous insulin therapy for diabetic ketoacidosis. Arch Intern Med 137: 1377-1380

24. Pickup JC, Home PD, Bilous RW, Keen H, Alberti KGMM (1981) Management of severely brittle diabetes by continuous subcutaneous and intramuscular insulin infusions: evidence for a defect in subcutaneous insulin absorption. Br Med J 282:347-350

25. Barbosa J, Menth L, Eaton J, Sutherland D, Freier EF, Najarian J (1981) Long-term, ambulatory, subcutaneous insulin infusion versus multiple daily injections in brittle diabetic patients. Diabetes Care 4: 266-274

26. Rudolf NCJ, Coustan DR, Sherwin RS, Bates SE, Felig P, Genel M, Tamborlane WV (1981) Efficacy of the insulin pump in the home treatment of pregnant diabetics. Diabetes 30:891-895

27. Jovanovic L, McDermott K, Peterson C (1982) Glucose and insulin requirements during labour in insulin-dependent diabetes. $J$ Clin Endocrinol Metab 50:862-866

28. Caplan RH, Pagliara AS, Geguin EA, Smiley CA, Bina-Frymark M, Goettl KA, Hartigan JM, Tankersley JC, Peck TM (1982) Constant intravenous insulin infusion during labor and delivery in diabetes mellitus. Diabetes Care 5: 6-10

29. Erwald R, Hed R, Nygren A, Rojdmark S and Weichel K (1974) Comparison of the effect of intraportal and intravenous infusion of insulin on blood glucose and free fatty acids in peripheral venous blood of man. Acta Med Scand 195:351-357

30. Santiago J, Clemens A, Clarke W, Kipnis D (1979) Closed-loop and open-loop devices for blood glucose control in normal and diabetic subjects. Diabetes 28: 71-81

31. Schade DS, Eaton RP, Friedman N, Spencer W (1979) The intravenous intraperitoneal and subcutaneous routes of insulin delivery in diabetic man. Diabetes 28: 1069-1072

32. Irsigler K, Kritz H (1979) Long-term continuous intravenous insulin therapy with a portable insulinotherapy with a portable insulin dosage-regulating apparatus. Diabetes 28: 196-203

33. Poulsen JSD, Smith M, Deckert M, Deckert T (1980) Comparison of intraperitoneal and intravenous insulin infusion. Acta Endocrinol 95: 500-504

34. Mirouze J, Selam JL, Pham TC, Chenon D (1980) Programming of an open-loop system for intravenous insulin infusion in insulin dependent diabetes. Acta Diabetol Lat 17: 103-109

35. Botz C, Leibel B, Zingg W, Gander R, Albisser A (1976) Comparison of peripheral and portal routes of insulin infusion by a computer controlled insulin infusion system (artificial endocrine pancreas) Diabetes 25:691-700

36. Pickup JC, Keen H, White MC, Parsons JA, Alberti KGMM (1979) Long-term continuous subcutancous insulin infusion in diabetic at home. Lancet 2:870-873

37. Peterson CM, Jones RL, Dupuis A, Levine BS, Bernstein R, Oshea M (1980) Feasibility of improved blood glucose control in patients 
with insulin dependent diabetes mellitus. Diabetes Care 2: $235-239$

38. Champion MC, Shepherd GAA, Rodger WW, Dupre J (1980) Continuous subcutaneous infusion of insulin in the management of diabetes mellitus. Diabetes 29:206-212

39. Tamborlane WV, Sherwin RS, Genel M, Felig P (1980) Outpatient treatment of juvenile-onset diabetes with a preprogrammed portable subcutaneous insulin infusion system. Am J Med 68: 190-196

40. Nathan D, Lou P, Avruch JR (1982) A crossover study of intensive conventional and insulin pump therapies in adult Type I diabetics. Ann Intern Med 97: 31-40

41. Albisser AM, Lougheed WD, Perlman K, Bahoric A (1980) Nonaggregating insulin solutions for long-term glucose control in experimental and human diabetes. Diabetes 29:241-243

42. Lougheed WD, Woulfe-Flanagan H, Clement JR, Albisser AM (1980) Insulin aggregation in artificial delivery systems. Diabetologia 19: 1-9

43. Bringer J, Heldt A, Grodsky GM (1981) Prevention of insulin aggregation by dicarboxylic amino-acids during prolonged infusion. Diabetes 30: 83-86

44. Schade DS, Eaton RP, Spencer W (1979) The peritoneal absorption of insulin in diabetic man: a potential site for a mechanical insulin delivery system. Metabolism 28: 195-197

45. Slama G, Buu KNP, Tchobroutsky G (1979) Plasma insulin and C-peptide levels during continuous subcutaneous insulin infusion. Diabetes Care 2: 251-255

46. Rizza RA, Westland RE, Hall LD, Patton G, Haymond MW, Clemens AH, Gerich JE, Service FJ (1982) Subcutaneous versus intraperitoneal administration of insulin on post-prandial hyperglycaemia and glucose turnover in alloxan diabetic dogs. Diabetologia 23:61-64

47. Mirouze J, Selam JL (1983) Clinical experience in human diabetic with portable and implantable insulin minipumps. Life Support Systems 2:39-50

48. Selam JL, Slingeneyer A, Hedon B, Mares P, Mirouze J (1983) A nonsurgical technique of peritoneal access for chronic insulin infusion. Diabetes Care 6: 105-111

49. Irsigler K, Kritz H, Hagmuller M, Franetzki M, Prestele K, Thurow H, Geisen K (1981) Long-term continuous intraperitoneal insulin device. Diabetes 30: 1072-1075

50. Schade DS, Eaton RP, Spencer WJ, Edward WS, Doverneck R (1981) Implantation of a remotely controlled insulin pump in diabetic man Diabetes 30 (Suppl 1): 15 A (Abstract)

51. Selam JL, Slingeneyer A, Chaptal PA, Franetzki M, Prestele K, Mirouze J (1982) Total implantation of a remotely controlled insulin minipump in a human insulin dependent diabetic. Preliminary results. Artificial Organs 6: 315-318

52. Rupp WM, Barbosa JJ, Blackshear PJ, McCarthy HB, Rohde TD, Goldenberg FJ, Rublein TG, Dorman FD, Buchwald H (1982) The use of an implantable insulin pump in the treatment of Type II diabetes. New Engl J Med 307: 265-270

53. Service FJ, Rizza RA, Gerich JE (1982) Implantation of insulin infusion devices. JAMA 247: 1866-1867

54. Center for Disease Control (1982) Use of continuous subcutaneous insulin infusion pumps. Georgia, Maine and Nebraska Morbid Mortal Weekly Report 31:5-15

56. Center for disease control (1982) Deaths among patients using continuous subcutaneous insulin infusion pumps. United States Morbid Mortal Weekly Report 31:80-87

56. Williamson JR, Bahoric A, Perlman K, Albisser AM (1982) Secondary amyloidosis in (beagle) dogs receiving intravenous insulin via mechanical pumps. Diabetes 31 (Suppl 2): $50 \mathrm{~A}$ (Abstract)

57. Pietri A, Raskin P (1981) Cutaneous complications of chronic continuous subcutaneous insulin infusion therapy. Diabetes Care 4: 624-626

58. Levandoski LA, White NH, Santiago JV (1982) Localized skin reactions to insulin: insulin lipodystrophies and skin reactions to pumped subcutaneous insulin therapy. Diabetes Care 5 (Suppl 1): $6-10$
59. Lock DR, Rigg LA (1981) Hypoglycemic coma associated with subcutaneous insulin infusion by portable pump. Diabetes Care $4: 389-391$

60. Boden G, Reichard GA Jr, Hoedltke RD, Rezvani I, Owen OE (1981) Severe insulin-induced hypoglycaemia associated with deficiencies in the release of counter-regulatory hormones. New Engl J Med 305: 1200-1205

61. Mirouze J, Collard F (1974) Continuous blood glucose monitoring in brittle diabetes. In: Malaise WJ, Pirart J (eds) Diabetes-Excerpta Medica, Amsterdam, pp 532-545

62. Krzentowski G, Scheen A, Luyckxx A, Lefebvre P (1982) Metabolic consequences of a 6 hour nocturnal interruption of a continuous subcutaneous insulin infusion pump. Diabetes 31 (Suppl 2): $67 \mathrm{~A}$

63. Rizza RA, Gerich JE, Haymond MW (1980) Control of blood sugar in insulin-dependent diabetes: comparison of an artificial endocrine pancreas, continuous subcutaneous insulin infusion and intensified conventional insulin therapy. New Engl J Med 303: $1313-1318$

64. Schiffrin A, Belmonte MM (1982) Comparison between continuous subcutaneous insulin infusion and multiple subcutaneous injections of insulin: a one yeat prospective study. Diabetes 31: 255-264

65. Felig P, Bergman M (1982) Intensive ambulatory treatment of insulin dependent diabetes. Ann Intern Med 97: 225-230

66. Mirouze J, Selam JL, Pham TC, Mendoza E, Orsetti A (1978) Sustained insulin-induced remissions of juvenile diabetes by means of an external artificial pancreas. Diabetologia 14: 223-227

67. Mirouze J, Selam JL, Pham TC, Orsetti A (1979) The external artificial pancreas: an instrument for induce remissions in severe recent juvenile diabetes. Comparison with a preprogrammed insulin infusion systems. In: Pfeiffer EF, Rak JF (eds) Feedback-controlled and preprogrammed insulin infusion in diabetes mellitus. Thieme, Stuttgart, pp 141-146

68. Mirouze J, Selam JL, Pham TC, Chenon D (1982) The outcome of juvenile ketotic diabetes following remissions induced by the artificial pancreas: a four-year follow-up. Horm Metab Res 12: $238-240$

69. Tamborlane WV, Sherwin RS, Genel M, Felig P (1979) Restoration of normal lipid and aminoacid metabolism in diabetic patients treated with a portable insulin-infusion pump. Lancet 1: 1258-1261

70. Dunn FL, Pietri A, Raskin P (1981) Plasma lipid and lipoprotein levels with continuous subcutaneous insulin infusion in Type I diabetes mellitus. Ann Intern Med 95: 426-431

71. Gancel A, Monnier L, Chantreuil J, Besse A, Crastes de Paulet A, Mirouze J (1982) Effets d'une perfusion continue d'insuline souscutanée sur les lipides plasmatiques et sur la fonction plaquettaire des diabétiques insulino-dépendants. Diabete Metab 8: 359

72. Raskin P, Pietri A, Unger R (1979) Changes in glucagon levels after four to five weeks of glucoregulation by portable insulin infusion pumps. Diabetes 28: 1033-1035

73. Gertner JM, Tamborlane WV, Horst RL, Sherwin RS, Felig P, Genel M (1980) Mineral metabolism in diabetes mellitus: changes accompanying treatment with a portable subcutaneous insulin infusion system. J Clin Endocrinol Metab 50: 862-866

74. Tamborlane WV, Sherwin RS, Koivisto V, Hendler R, Genel M, Felig P (1979) Normalization of the growth hormone and catecholamine response to exercice in juvenile-onset diabetic subjects treated with a portable insulin infusion system. Am J Med 68: 190-196

75. Tamborlane WV, Hintz RL, Bergman M, Genel M, Felig P, Sherwin RS (1981) Insulin infusion pump treatment of diabetes: influence of improved metabolic control on plasma somatomedin levels. New Engl J Med 305: 303-307

76. Shamoon H, Hendler R, Sherwin RS (1980) Altered responsiveness to cortisol, epinephrine and glucagon in insulin-infused juvenile-onset diabetics. Diabetes 29:284-291

77. Geffner ME, Kaplan SA, Lippe BM, Levin SR (1981) Overnight continuous subcutaneous insulin infusion (CSII): association 
with pre-breakfast hyperglycemia. Diabetes 30 (Suppl 1): 136A (Abstract)

78. Bolli G, Calabrese C, De Feo P, Compagnucci P, Zega G, Angeletti G, Cartechini MG, Santeusanio F, Brunetti P (1982) Lack of glucagon response in glucose counter-regulation in Type I diabetes: absence of recovery after prolonged optimal insulin therapy. Diabetologia 22: 100-105

79. Bleicher SJ, Lee TY, Bernstein R (1980) Effect of blood glucose control on retinal vascular permeability in insulin-dependent diabetes mellitus. Diabetes Care 3: 184-186

80. White MC, Kohner EM, Pickup JC, Keen H (1981) Reversal of diabetic retinopathy by continuous subcutaneous insulin infusion: a case report. Br J Ophthalmol 65: 307-311

81. White NM, Waltman SR, Krupin T, Santiago JV (1981) Reversal of early ocular abnormalities in juvenile diabetics (IDD) after normalization of hemoglobin Alc. Clin Res 29: 426 A

82. Hooymans JMM, Ballegooie EV, Schweitzer NMJ, Doorenbos $\mathrm{H}$, Reitsma WD, Sluiter WJ (1982) Worsening of diabetic retinopathy with strict control of blood sugar. Lancet 21: 438

83. Steno Study Group (1981) Effect of 6 months of strict metabolic control on eye and kidney function in insulin-dependent diabetics with background retinopathy. Lancet 1: 121-123

84. Viberti GC, Pickup JC, Jarrett RJ, Keen H (1979) Effect of control of blood glucose on urinary excretion on albumin and $\beta 2$-microglobulin in insulin-dependent diabetes. New Engl $\mathbf{J}$ Med 300: 638-641
85. Pitkanen E, Hulmi S (1982) Long-term subcutaneous insulin infusion therapy and progression of nephropathy in Type 1 (insulindependent) diabetes. Diabetologia 22: 378 (Abstract)

86. Slingeneyer A, Mion C (1982) Continuous ambulatory peritoneal dialysis in treatment of diabetics with end stage renal failure. Nefrologia 2:63-68

87. Pietri A, Ehle AL, Raskin P (1980) Changes in nerve conduction velocity after six weeks of glucoregulation with portable insulin infusion pumps. Diabetes 29:668-671

88. Troni W, Cantello R, Rainero E, Carta Q, Besello MG, Baselle MT (1982) Serial study of nerve conduction velocity in diabetic patients treated with continuous subcutaneous insulin infusion. Min Med (Endocrinol) 7:103-113

89. Direction du Plan: Assistance Publique (Hôpitaux de Paris) L'hospitalisation en 1979-1980 (1982) Rapport interne. Assistance Publique, Paris, France

90. Renan E (1879) Discours prononcés dans la séance publique tenue par l'Académie Française, le 3 Avril 1879. Firmin Didot ed. de l'Institut de France, pp 3-25

Professor J. Mirouze

Clinic of Metabolic and Endocrine Diseases

Hôpital Saint-Eloi

F-34059 Montpellier Cedex

France 